Ambiente \& Água - An Interdisciplinary Journal of Applied Science
ISSN 1980-993X - doi:10.4136/1980-993X
www.ambi-agua.net
E-mail: ambi.agua@gmail.com

\title{
A relação entre Planos Diretores Municipais e Planos de Bacias Hidrográficas na gestão hídrica
}

\author{
doi: 10.4136/ambi-agua.1394
}

Received: 09 May 2014; Accepted: 14 Apr. 2015

\section{Denise Gallo Pizella}

\author{
Universidade Estadual Paulista "Júlio de Mesquita Filho" (UNESP), Ilha Solteira, SP, Brasil \\ Departamento de Biologia e Zootecnia \\ e-mail: denise@bio.feis.unesp.br
}

\section{RESUMO}

A Política Nacional de Recursos Hídricos tem como um de seus instrumentos a elaboração de Planos de Recursos Hídricos de modo descentralizado. Tendo em vista o planejamento dos recursos hídricos e sua relação com o ordenamento territorial, o objetivo deste artigo é analisar as dificuldades e potencialidades de natureza institucional e jurídica para uma gestão integrada dos recursos hídricos. Para tanto, utilizou-se o método de pesquisa documental e bibliográfica, partindo da análise documental do Estatuto da Cidade e da literatura especializada sobre gestão das águas em âmbito municipal e de bacias hidrográficas. Em âmbito municipal, o Plano Diretor de uso e ocupação do solo se transformou no principal instrumento de gestão territorial e municipal, definindo os parâmetros para o cumprimento da função social, ambiental e econômica da propriedade. Neste sentido, os municípios possuem uma grande responsabilidade na proteção dos recursos hídricos e, sem seu apoio, não é possível integrar a gestão territorial e hídrica em âmbito de Bacia Hidrográfica. Apesar das dificuldades existentes quanto à inserção da variável ambiental no planejamento urbano, verifica-se a potencialidade de o Plano Diretor Municipal contribuir para uma gestão hídrica que seja ambientalmente sustentável e influencie na melhoria progressiva da qualidade e quantidade hídricas nas bacias hidrográficas. Por conseguinte, com uma participação mais expressiva do município no Comitê de Bacia, é possível que as formas de ocupação e uso do solo municipal sejam consideradas no momento de elaboração e execução dos Planos de Bacia. Assim, a gestão dos recursos hídricos pode se dar integradamente.

Palavras-chave: gestão das águas urbanas, gestão integrada dos recursos hídricos, planejamento de bacias hidrográficas.

\section{The relationship between the Municipal Master Plan and local Watershed Plans in water management}

\begin{abstract}
The National Water Resources Policy has as one of its tools the drafting of local Water Resource Plans. In view of water resources planning and its relationship to land use planning, the aim of this work is to analyze the institutional and legal difficulties and the potential for an integrated system of water resources management. For this, we used the method of documentary and bibliographic research, beginning with the "Estatuto da Cidade", a law for
\end{abstract}


urban policy in Brazil, and literature on water management at the municipal and watershed levels. At the municipal level, the "Master Plan" (municipal plan of land use planning) became the main instrument of territorial and municipal management, defining the parameters for the compliance of social, environmental and economic functions of real property. In this sense, the municipalities have a responsibility to protect water resources and, without local support, territorial and water management cannot be integrated in the context of the river basin. Despite the difficulties of including environmental variable in urban planning, the Master Plan has the potential to shape local water management systems that are environmentally sustainable and that progressively improve water quality and quantity within the watershed. Similarly, with more significant participation of the municipality in the Basin Committee, it is possible that the forms of municipal land use and occupation can be considered during the development and implementation of the Basin Plan. Thus, the management of water resources can occur integrally.

Keywords: integrated water resources management, urban water management, watershed planning.

\section{INTRODUÇÃO}

O marco inicial da política hídrica brasileira é o Código das Águas de 1934, elaborado em um período de florescimento do setor industrial no país e tendo por objetivo principal a regulação do uso das águas doces superficiais para a hidroeletricidade. No entanto, sendo ainda então o setor agrícola o maior contribuinte para a geração de divisas nacionais, o responsável pela execução do referido Código é o Ministério da Agricultura, até o ano de 1961, quando pressões do setor hidroelétrico direcionam sua transferência para o Ministério de Minas e Energia, por meio do Departamento Nacional de Águas e Energia Elétrica (DNNAEE) (Leal, 1998).

$\mathrm{Na}$ década de 1980, os conflitos entre os múltiplos usuários da água por conta do aumento da construção de hidrelétricas e a poluição hídrica causada pela ausência de tratamento dos esgotos domiciliares e industriais, assim como o aumento das demandas por irrigação, conduzem a pressões sociais pela gestão do setor por uma entidade autônoma e não usuária do recurso. Deste modo, o Poder Executivo propõe a criação de um Sistema de Gerenciamento de Recursos Hídricos que elabora a Política Nacional de Recursos Hídricos (PNRH) (Lei nº. 9433/97), promulgada em 1997 (Leal, 1998; Peres e Silva, 2013).

Anteriormente à criação da Política Nacional de Recursos Hídricos, a Constituição Federal de 1988 define as águas como um bem de uso comum e modifica sua dominialidade. Por meio de seu artigo 20, inciso III, indica que, entre os bens da União, encontram-se: "os lagos, rios e quaisquer correntes de água em terrenos de seu domínio, ou que banhem mais de um Estado, sirvam de limites com outros países, se estendam a território estrangeiro, ou dele provenham, bem como terrenos marginais e as praias fluviais". Já entre os bens do Estado e do Distrito Federal, se situam "as águas superficiais ou subterrâneas, fluentes, emergentes e em depósito, ressalvadas, neste caso, na forma da lei, as decorrentes de obras da União" (Brasil, 1988).

A Política Nacional de Recursos Hídricos define a responsabilidade pela gestão hídrica, que se dá em âmbito de bacias hidrográficas, de forma descentralizada e sendo compartilhada pela União, Estados e Municípios, além de constituir o Sistema Nacional de Gerenciamento de Recursos Hídricos e estabelecer os instrumentos de gestão, quais sejam: o Plano Nacional de Recursos Hídricos, o enquadramento das águas doces superficiais em classes de qualidade; a outorga e a cobrança pelo uso dos recursos hídricos e, por fim, o Sistema Nacional de Informações sobre Recursos Hídricos. Além disto, é garantida a participação pública na gestão hídrica (Brasil, 1997).

A bacia hidrográfica é considerada a melhor unidade territorial para o planejamento e a

Rev. Ambient. Água vol. 10 n. 3 Taubaté - Jul. / Sep. 2015 
gestão ambiental por ser um sistema onde todas as ações antrópicas e naturais que ocorrem em seu espaço se refletem na qualidade e quantidade da malha hídrica que nela se faz presente (Jouravlev, 2003).

No Brasil, a planificação dos recursos hídricos é realizada em âmbito federal pelo Ministério do Meio Ambiente, pelas secretarias estaduais de recursos hídricos em âmbito estadual e, por fim, em relação ao recorte geográfico das bacias hidrográficas, pelos Comitês de Bacia. Estes são órgãos colegiados, com estrutura tripartite (onde participam representantes do poder público, dos usuários dos recursos hídricos e da sociedade civil organizada) que tomam decisões a respeito de atividades e políticas públicas que interfiram na qualidade e quantidade das águas em seu espaço geográfico e possuem como atribuições (Jacobi, 2005; ANA, 2011):

- promover o debate sobre os temas relacionados à água e coordenar as entidades que atuam em sua gestão;

- arbitrar os conflitos relacionados com os recursos hídricos;

- aprovar os planos de recursos hídricos realizados para a bacia hidrográfica, assim como acompanhar sua execução e propor medidas para o cumprimento de suas metas e;

- estabelecer mecanismos de cobrança pelo uso água e sugerir os valores a serem cobrados, assim como a aplicação dos recursos arrecadados.

Definida não somente como um espaço dotado de uma dimensão física, mas também social, a bacia hidrográfica exerce uma influência sobre os usos do solo, por abranger os municípios em seu território, mas cuja gestão excede naturalmente as fronteiras políticoadministrativas e, consequentemente, gerando conflitos de objetivos entre as unidades territoriais regional e municipal (Peres e Silva, 2013).

A Política Nacional de Recursos Hídricos tem como um de seus instrumentos a elaboração de Planos de Recursos Hídricos (PRH), definidos como planos diretores de longo prazo que fundamentam a implementação da Política Nacional de Recursos Hídricos e seu gerenciamento. Dentre os Planos de RH, situam-se os Planos de Bacias Hidrográficas a serem elaborados pelos Comitês de Bacia Hidrográfica (Brasil, 1997).

Enquanto que os Planos de Bacia estabelecem as diretrizes para a gestão hídrica em âmbito regional, os municípios definem as suas políticas urbanas, que geram impactos ambientais positivos e negativos de diversas magnitudes sobre os recursos hídricos em âmbito local/municipal, por meio de seu ordenamento territorial e dos usos do solo. Para melhor regulamentar as formas de concepção e uso do espaço no ambiente urbano, a Constituição Federal de 1988 apresenta como instrumento o Plano Diretor Municipal, regulamentado pela Lei $\mathrm{n}^{\circ}$. 10.257/2001, o Estatuto da Cidade, e que se transformou no principal instrumento de gestão territorial e municipal, definindo os parâmetros para o cumprimento da função social, ambiental e econômica da propriedade (Peres e Silva, 2013).

Neste sentido, por estabelecerem as políticas de disciplinamento do uso do e ocupação do solo, os municípios possuem uma grande responsabilidade na proteção dos recursos hídricos e, sem seu apoio, não é possível integrar a gestão territorial e hídrica em âmbito de bacia hidrográfica (Vasconcelos e Silva, 2013).

Por sua vez, considerando que os Planos de Bacias Hidrográficas tem a atribuição de delinear os objetivos e metas para a gestão hídrica em âmbito regional, há a possibilidade de que apontem diretrizes aos Planos Diretores Municipais no que tange à expansão urbana, a proteção de mananciais, a localização de indústrias e normas para o setor de irrigação e saneamento, sendo um importante instrumento para a análise de atividades humanas que possam afetar os recursos hídricos de forma significativa (Peres e Silva, 2013).

Como gestão integrada dos recursos hídricos, se entende as políticas, planos, programas e atividades que levem em conta as inter-relações entre o crescente desenvolvimento econômico e a disponibilidade das águas superficiais e subterrâneas. Neste sentido, é necessária a 
integração entre as atividades setoriais que impactam os recursos hídricos (agricultura, uso e ocupação do solo nas cidades e seu crescimento, indústrias, aproveitamentos hidrelétricos, dentre outros), a coordenação das instituições governamentais e não governamentais que são responsáveis ou atuam na gestão territorial e dos recursos hídricos e a participação social nas tomadas de decisão (Carter et al., 2005).

Deste modo, Carneiro et al. (2008) levantam questões a respeito do relacionamento entre a gestão de recursos hídricos por bacias hidrográficas e em âmbito municipal, ou seja, como a questão do uso do solo se insere nos planos de bacia hidrográfica e como a gestão dos recursos hídricos se insere nos planos diretores municipais. Tendo em vista tais questionamentos, o presente artigo busca analisar, de modo não exaustivo, as dificuldades e potencialidades de natureza institucional e jurídica para uma gestão hídrica integrada que considere o planejamento do uso e ocupação do solo nos municípios brasileiros e os Planos de Bacia Hidrográfica. Para tanto, utilizou-se o método de pesquisa documental e de análise bibliográfica, partindo da análise documental do Estatuto da Cidade e da literatura especializada sobre gestão das águas em âmbito municipal e no âmbito de bacias hidrográficas.

\section{DESENVOLVIMENTO}

O crescimento acelerado das cidades na última metade do século XXI e os consequentes impactos de ordem ambiental e social levaram à necessidade de se criar instrumentos que regulamentassem a ocupação do solo no meio urbano. Deste modo, a Constituição Federal de 1988 insere, no Capítulo II do Título VII, dirigido à ordem econômica e financeira, a Política Urbana. O fato de não ser integrada, assim como a questão do Meio Ambiente, no Título VI da Carta Magna (Da Ordem Social), provoca discussões entre juristas, visto que a problemática urbana, ao tratar de assentamentos humanos e, portanto, do espaço físico e social das interações coletivas, é mais afeita à temática social do que econômica. Provavelmente, argumenta-se, tal fato se deu em decorrência das condições históricas de elaboração da Lei Maior, com o constituinte enfatizando o direito à propriedade urbana e seu uso, visto que o crescimento urbano conduz às distorções de valores econômicos nos meio urbano, como a especulação imobiliária e a exclusão social. Segundo Milaré (2005), tais questões não se dissociam àquelas de cunho ambiental, já que a Constituição Federal deve ser interpretada em seu conjunto, estando a esfera do meio ambiente ecologicamente equilibrado integrada nas relações econômicas.

Dada a necessidade de regulamentar os objetivos e instrumentos da política urbana, notadamente os artigos 182 e 183 da Constituição, foi promulgada em 2001, após 12 anos de tramitação no Congresso Nacional, a Lei ${ }^{\circ}{ }^{10.257}$, denominada Estatuto da Cidade. Por meio desta lei, de acordo com a Constituição da República Federativa do Brasil, título VII, artigo 30 (Brasil, 1988) há a promoção de um adequado "ordenamento territorial, mediante planejamento e controle do uso do solo urbano", delimitando diretrizes de acesso e uso da propriedade urbana (Bassul, 2002; Milaré, 2005).

Em relação à propriedade e seu direito de uso, a Carta Magna estabelece, por meio do artigo 5 do Título II, que trata dos Direitos e Garantias Fundamentais e do artigo 186, que é garantido o direito à propriedade, sendo que esta deve atender à sua função social e ambiental. Deste modo, a proteção ambiental é um dever que se encontra incluso no direito à propriedade, tanto no meio urbano quanto no rural, sendo que a função social e ambiental da propriedade modifica o direito do proprietário de utilizá-la livremente, condicionando seu uso ao interesse não somente econômico, mas também destas duas vertentes (Milaré, 2005).

Para Bassul (2002), o Estatuto da Cidade possui um importante papel no direito urbanístico ao balizar os municípios e os movimentos sociais citadinos com instrumentos que 
buscam garantir aos cidadãos o direito à cidade, definido nesta lei como "o direito à terra urbana, à moradia, ao saneamento ambiental, à infra-estrutura urbana, ao transporte e aos serviços públicos, ao trabalho e ao lazer, para as presentes e futuras gerações" (Brasil, 2001). Neste sentido, para possibilitar as diretrizes gerais da política urbana, tais como "direito às cidades sustentáveis; participação popular; cooperação entre agentes públicos e privados; planejamento do desenvolvimento das cidades; proteção ao meio ambiente natural e do patrimônio cultural; produção de bens e serviços nos limites da sustentabilidade ambiental" (Bassul, 2002), a Lei apresenta diversos instrumentos, dentre os quais se encontram os Planos Diretores municipais. Estes apresentam as normas obrigatórias para o planejamento municipal e sua elaboração é compulsória nos seguintes casos: municípios com mais de 20.000 habitantes, integrantes de regiões metropolitanas e aglomerações urbanas, integrantes de áreas de especial interesse turístico e inseridos em área de influência de empreendimentos ou atividades com significativo impacto ambiental de âmbito regional ou nacional (Brasil, 2001). O planejamento é, neste sentido, fundamental para que haja a ordenação do crescimento e das transformações que ocorrem na cidade e no campo, considerando a função social e ambiental do espaço (Machado, 2013).

Segundo Milaré (2005), o Plano Diretor é um desdobramento da Lei Maior do Munícipio, qual seja, a Lei Orgânica Municipal. Considerando as características dinâmicas do município, é um instrumento que deve ser submetido a revisões periódicas, sendo que a Política Nacional Urbana as prescreve em intervalos de 10 anos. Quanto à sua elaboração, deve ser realizada de modo a não somente permitir, mas a incentivar a participação dos cidadãos em suas diversas etapas, de modo transparente. Sendo um importante instrumento de gestão ambiental municipal, é imperioso que a comunidade tenha o controle sobre seus rumos e aplicação, visto, sobretudo, a ausência de uma prática de planejamento na rotina das Administrações Públicas.

A Constituição Federal de 1988 atribuiu, como anteriormente mencionado, uma grande importância aos municípios em relação à gestão ambiental, por considerá-los um espaço propício a ações participativas ao envolver diretamente seus habitantes no delineamento da agenda ambiental almejada. No entanto, apesar de ser concebido como uma unidade territorial privilegiada, por se encontrar mais próximo às realidades sociais, o munícipio não pode assumir o papel de gestor ambiental exclusivo, pois seu recorte espacial fornece somente uma visão fragmentada da realidade. Em se tratando de recursos hídricos, objeto de análise deste artigo, tal limitação é evidente, já que a malha hídrica presente no território municipal é apenas um pequeno recorte de uma dinâmica hidrológica mais ampla, cuja gestão é mais bem concebida em termos de bacias hidrográficas (Castro et al., 2005).

Os espaços urbanos contribuem sobremaneira com o carreamento de fontes poluidoras nos mananciais, além de contribuir para a descaracterização do ambiente natural com loteamentos irregulares e demais equipamentos urbanos que são incompatíveis com a capacidade de suporte do meio. Dadas as interferências que as cidades promovem no ciclo da água, notadamente com a expansão urbana sem planejamento adequado, é crescente, deste modo, a necessidade de se adotar a bacia hidrográfica como unidade de gestão, assim como considerar a ocupação do solo urbano como prioritária para a gestão hídrica (Silva e Porto, 2003; Pinto, 2007).

Para Carter et al. (2005), uma gestão integrada das águas consiste em um novo paradigma para a gestão hídrica, na medida em que considera a inter-relação entre os recursos hídricos (superficiais e subterrâneos) e os usos múltiplos que os humanos fazem deles, assim como as necessidades de manter padrões de qualidade hídrica para o funcionamento dos ecossistemas aquáticos. Somente deste modo é possível se fazer uma gestão sustentável das águas, que possibilite sua utilização em longo prazo, por meio de sistemas de planejamento integrado. 
A atuação dos municípios como gestores dos recursos hídricos se efetiva por meio de sua participação nos Comitês de Bacias Hidrográficas, na medida em que compõem o Sistema Integrado de Gerenciamento de recursos Hídricos (SIGRH). No entanto, por ser o local onde as pessoas reproduzem sua cultura e os impactos ambientais são gerados devido aos usos inadequados do solo, se configuram como importantes partícipes na gestão hídrica. Além disto, cabem à municipalidade as decisões quanto ao ordenamento territorial, à proteção e fiscalização do uso de seus recursos naturais e a regulação de suas atividades econômicas. Dentre as questões locais que impactam os recursos hídricos sob responsabilidade da gestão municipal se encontram a coleta e adequada disposição final dos resíduos sólidos, a proteção dos mananciais e a drenagem urbana. Em relação ao abastecimento de água e coleta e tratamento de esgotos domiciliares, as atribuições podem estar a cargo das prefeituras municipais, do estado ou de concessionárias.

Quanto à função legiferante municipal, Machado (2013) afirma que o município não possui a atribuição de legislar sobre águas, mas tem o dever de aplicar a Política Nacional dos Recursos Hídricos em seu ordenamento territorial. A título de exemplificação, apesar de não ser agente gestor de águas, cabe ao município zelar pela proteção de mananciais, muitos dos quais se encontram, em diversas localidades brasileiras, seriamente ameaçados por contaminação de origem pontual e difusa. Neste sentido, o município descumpre seu papel constitucional de zelar pela proteção ambiental em âmbito local. Ao tratar da degradação dos mananciais utilizados para abastecimento da Região Metropolitana de São Paulo, Silva e Porto (2003) apontam como única solução ao problema um atrelamento entre a gestão territorial urbana e dos recursos hídricos.

Dentre os instrumentos de que o município dispõe para implementar as diretrizes do Plano de Bacias, o Plano Diretor Municipal se constitui em uma importante ferramenta para o planejamento urbano em bases sustentáveis, pois, se elaborado considerando a variável ambiental no processo de controle do uso e ocupação do solo, incorpora à tradicional função econômica da propriedade privada a dimensão socioambiental. Deste modo, torna-se possível restringir a expansão urbana e ocupação imobiliária em áreas impróprias para edificações decorrentes de fragilidades ambientais locais, tais como ocorrem em áreas alagadiças, em terrenos íngremes, em áreas de preservação permanente e em áreas de mananciais (Carneiro et al., 2008).

Para Machado (2013) há uma complementaridade entre Planos Diretores Municipais e de Bacias quanto à gestão hídrica, considerando-se que, no planejamento territorial municipal, deve-se levar em conta a realidade do ecossistema em que o município se encontra e não somente os aspectos sociais, econômicos e políticos que se inserem em suas fronteiras. Neste sentido, o recorte territorial deve abranger a bacia e sub-bacias hidrográficas em que se situa, adaptando o planejamento territorial às diretrizes presentes no Plano de Bacia Hidrográfica de que faz parte. Salienta para o fato de que o município, como integrante do Comitê de Bacia, tem a oportunidade de opinar e votar na elaboração do Plano de Bacia, interferindo neste processo, portanto. Ao mesmo tempo, é explícita a vinculação entre os Planos de Recursos Hídricos e o Plano Diretor no Estatuto da Cidade, em seu artigo 42-A, parágrafo $2^{\circ}$. (Brasil, 2001), que menciona "O conteúdo do plano diretor deverá ser compatível com as disposições insertas nos planos de recursos hídricos, formulados consoante a Lei ${ }^{\circ} 9.433$, de 8 de janeiro de 1997'.

A importância do município na elaboração do Plano de Bacia se dá nas diversas fases de sua elaboração. Na etapa diagnóstica, por exemplo, quando se busca informações a respeito da situação atual dos recursos hídricos em termos quali-quantitativos, as principais pressões exercidas sobre os mesmos e as demandas relativas aos diversos usos que se faz destes recursos na bacia (Brasil, 1997). Nesta fase, o Comitê de Bacia coleta uma série de informações junto aos órgãos responsáveis pela outorga de usos dos recursos hídricos 
concedida aos municípios; a existência, quantidade e captação de água de mananciais; a qualidade das águas utilizadas para abastecimento; existência de Planos de Saneamento; índice de coleta e tratamento de esgotos domiciliares; existência de erosões na área do município; informações sobre a coleta, tratamento e disposição final de resíduos sólidos urbanos, dentre outras informações pertinentes à gestão hídrica.

A partir deste conhecimento e de outras informações coletadas juntamente aos órgãos estaduais e federais, é possível elaborar o prognóstico do Plano de Bacia, que constitui as metas de curto, médio e longo prazo da região, e que tem por diretriz a melhora progressiva dos recursos hídricos em qualidade e quantidade, impactando diretamente os municípios, que necessitam traçar estratégias para o alcance desta melhoria em suas áreas de atuação. Percebese, nestes dois momentos de elaboração do Plano de Bacia, o papel da gestão local dos recursos hídricos tanto no fornecimento de informações indispensáveis como na consecução das metas estipuladas.

Apesar de os municípios terem sua participação assegurada na gestão das Bacias na condição de usuários e, portanto, atuando no SINGRH somente como consumidores ou prestadores de serviços (nos casos em que assumem de forma direta ou indireta, a responsabilidade pelo abastecimento doméstico e o esgotamento sanitário) (Santos e Medeiros, 2009), há, no entanto, indefinições em seu papel de formulador e executor de políticas urbanas que impactam os recursos hídricos em seu âmbito de atuação legal, seja por meio de Planos Diretores do uso e ocupação do solo ou por outros mecanismos de gestão. No entanto, ao estabelecer objetivos e critérios para atender o modelo de cidade almejado por parte de seus cidadãos e concretizar o planejamento do solo municipal por meio da divisão do espaço em zonas de usos preferenciais, o Plano Diretor municipal interfere diretamente sobre os aspectos hidromorfológicos, qualitativos e quantitativos das águas presentes em seu território (Carneiro et al., 2008).

Considerando que a relação entre uso e ocupação do solo e problemas ambientais é bem documentada na literatura, Carneiro et al. (2008) levantam o despreparo das administrações municipais no sentido de efetivar as metas delineadas nos Planos Diretores em suas práticas cotidianas de autorização de loteamentos e obras de infraestrutura, impossibilitando uma gestão adequada dos recursos hídricos. Ao mesmo tempo, não há a consideração desta vertente de planejamento territorial nos órgãos responsáveis pela gestão dos recursos hídricos, o que transparece nos Planos de Bacia em suas fases de diagnóstico e prognóstico.

Em uma pesquisa realizada por Empinotti (2010) acerca da avaliação dos 20 anos do Sistema Integrado de Gerenciamento de Recursos Hídricos no estado de São Paulo, foram entrevistados representantes dos três segmentos do SIGRH, quais sejam: estado, municípios e sociedade civil. Esta pesquisa apontou diversas conquistas e obstáculos existentes no Sistema, com destaque para a gestão integrada de recursos hídricos. Neste interim, os entrevistados avaliaram a baixa integração entre estado, municípios e bacia na atuação sobre matérias de competências concorrentes, tais como o uso do solo, que deveria ser planejado de forma conjunta.

Do mesmo modo, externalizaram que os Planos Diretores Municipais e outros planos setoriais que influenciam a dinâmica dos recursos hídricos não contemplam em seu bojo os Planos de Bacia ou os Planos Estaduais de Recursos Hídricos. Além disto, os dados fornecidos pelas prefeituras para contemplar o diagnóstico dos Planos de Bacia apresentam deficiências e incertezas, já que não há obrigatoriedade na geração e fornecimento destas informações, que não são acompanhadas de documentação que ateste sua veracidade. Por conta disto, argumenta-se sobre a necessidade de revisão dos critérios e métodos de coleta destes dados, a fim de tornar estas importantes informações mais confiáveis (Empinotti, 2010).

Devido a questões de natureza política, institucional e legal, tais obstáculos dificultam a 
articulação entre a gestão de recursos hídricos em âmbito de bacias hidrográficas e na municipalidade, porém, devido a necessidade de integração entre estas duas esferas de planejamento para a efetiva proteção hídrica, é importante conduzir esforços no sentido de sanar os problemas existentes, buscando as sinergias possíveis (Carneiro et al., 2008; Peres e Silva, 2012).

Para tanto, os Planos Diretores Municipais devem inserir as diretrizes presentes nos Planos de Recursos Hídricos com mecanismos de controle e fiscalização por parte dos cidadãos e da administração pública que garantam seu cumprimento. Do mesmo modo, os Comitês de Bacia Hidrográfica necessitam considerar o planejamento de uso do solo em âmbito municipal e suas influências sobre os recursos hídricos na bacia hidrográfica como um todo.

A participação ativa dos municípios nos Comitês de Bacia hidrográfica, sobretudo no processo de elaboração dos Planos de Bacia possibilita que o município não se posicione como um simples usuário dos recursos hídricos, desempenhando o limitado papel de fornecer dados para a composição da etapa diagnóstica do Plano e como tomador de recursos do Fundo Estadual de Recursos Hídricos (FEHIDRO), como se dá no Estado de São Paulo. O município necessita elaborar seu próprio diagnóstico e prognóstico socioambiental na forma de zoneamentos ambientais para que o Plano reflita a situação real da bacia e opinar em sua fase prognóstica, onde serão definidas as metas de melhoria progressiva da qualidade das águas doces superficiais, os termos de outorgas sobre o uso dos recursos hídricos, a cobrança pelo uso das águas, o enquadramento dos cursos d'água, dentre outras questões.

O município pode atuar, também, sendo órgão do SINGRH, como retroalimentador do Sistema de Informações sobre Recursos Hídricos, um instrumento da PNRH de fundamental importância para o planejamento de recursos hídricos. Como participantes do Sistema em âmbito municipal podem-se considerar o Departamento de Águas, o qual, se presente, é o órgão responsável pelo abastecimento urbano e, em alguns casos, pela coleta e tratamento de esgotos, além da Secretaria de Meio Ambiente.

$\mathrm{Na}$ condição de usuário de recursos hídricos, compete ao município a criação de campanhas educativas visando seu uso racional por parte dos cidadãos, seja nas residências, nos espaços públicos, na agropecurária e nas indústrias de forma geral. As políticas municipais de educação ambiental, de elaboração de Agendas 21 e planejamentos estratégicos que contemplem a gestão hídrica são importantes ferramentas para a consecução deste objetivo (Tundisi e Matsumura-Tudisi, 2011).

Juntamente ao Plano Diretor Municipal, o Zoneamento se constitui em uma importante ferramenta para a prevenção dos impactos ambientais decorrentes da ocupação desordenada do solo nas cidades. Ao indicar as áreas prioritárias para conservação ambiental (no caso, mananciais, nascentes, rios, Reservas Legais, áreas verdes urbanas, dentre outros espaços) é um instrumento importante para minimizar problemas ambientais derivados de ocupações humanas inadequadas já existentes no município e planejar futuras áreas de expansão e de localização de empreendimentos significativamente impactantes, de modo a conferir algum nível de proteção às águas superficiais e subterrâneas que abrangem o recorte municipal. No entanto, sua elaboração requer a participação da sociedade, a fim de que interesses especulativos sobre a terra e soluções pontuais aos problemas ambientais urbanos e rurais não prevaleçam.

Além do Plano Diretor Municipal e do Zoneamento construídos de forma participativa, outras estratégias podem ser adotadas no âmbito municipal para efetivar a gestão integrada dos recursos hídricos, tais como a participação do município no SINGRH como agente que forneça dados locais para o aprimoramento do Sistema de Informações sobre Recursos Hídricos; na criação e execução de uma política de educação ambiental que promova a cidadania ambiental em torno do uso racional da água; na consideração da variável hídrica no 
licenciamento ambiental de atividades potencialmente poluidoras de abrangência local (para os municípios que possuam competência quanto ao licenciamento) e no cumprimento de sua função como agente executor e fiscalizador das políticas ambientais elaboradas em âmbito federal e estadual.

A criação de consórcios municipais organizados em bacias hidrográficas, como o caso do Consórcio Piracicaba/Capivari, em São Paulo, ou o Lagos São João, no Rio de Janeiro, tem se apresentado como um mecanismo importante para a gestão dos recursos hídricos, ao possibilitar uma maior descentralização e participação social no planejamento local das águas. A realização destes consórcios se faz presente nas constituições estaduais, que permitem aos municípios a associação para o alcance de objetivos diversos, mediante aprovação das respectivas câmaras municipais. Além disto, a PNRH também os prevê em suas diretrizes (Almeida e Pereira, 2009).

\section{CONCLUSÕES}

A Constituição Federal Brasileira de 1988 trouxe em seu bojo o federalismo, onde os três entes da federação (União, Estados e municípios) possuem atribuições legais e de fiscalização da política ambiental em caráter complementar ou suplementar. Neste sentido, conferiu-se autonomia municipal para o estabelecimento das diretrizes ambientais em sua esfera de competência.

No tocante às águas, entretanto, tal autonomia não é possibilitada, visto que os Planos de Recursos Hídricos, a outorga, cobrança pelo uso dos recursos hídricos e o enquadramento dos cursos d'água são instrumentos da Política Nacional dos Recursos Hídricos a serem implementados pelo SINGRH, sendo os Comitês de Bacias Hidrográficas os órgãos colegiados que tomam as decisões e garantem que as águas atendam aos diversos interesses da população e da conservação ambiental nas bacias hidrográficas. Considerando que as ações que impactam diretamente os recursos hídricos se dão na escala do município, este tem sua representatividade garantida nos Comitês de Bacia como usuários, com poder de influenciar sobremaneira a elaboração e consecução dos objetivos atuais e futuros dos Planos de Bacia.

Ao mesmo tempo, o município possui um importante papel na gestão sustentável de suas águas, na medida em que é responsável pelas políticas públicas de resíduos sólidos, drenagem urbana, abastecimento e, em diversos casos, de coleta e tratamento de esgotos domiciliares, assim como de criação e manutenção de áreas verdes. A política urbana, que regulamenta os usos e ocupações do solo e ordena o território municipal exerce, portanto, grande impacto sobre os recursos hídricos.

Apesar das dificuldades de cunho institucional e jurídico que dificultam a gestão integrada dos recursos hídricos e as consequências que este fato acarreta para que haja um planejamento eficaz de curto, médio e longo prazos dos usos múltiplos das águas de modo mais equitativo e ampliando as possibilidades de manutenção e melhorias dos ecossistemas aquáticos, o presente artigo apontou de modo não exaustivo, as contribuições do Plano Diretor Municipal e de outros instrumentos, que possibilitem sua efetivação. Do mesmo modo, teceu considerações acerca da incorporação das diretrizes deste Plano no momento de elaboração e revisão dos Planos de Bacias Hidrográficas.

No processo de elaboração do Plano Diretor, se faz necessária a consideração do binômio disponibilidade versus demanda hídrica, a fim de garantir que o espaço da cidade seja planejado de modo a evitar e minimizar os impactos negativos aos recursos hídricos. Sendo um instrumento a ser construído de modo participativo, ao menos em teoria, é importante que a sociedade se mobilize de fato e de modo consciente em termos ambientais para exercer um maior controle social quanto ao futuro coletivamente almejado para a cidade e fazendo cumprir as funções sociais e ambientais da propriedade e do direito de construir. 
Apesar das dificuldades existentes quanto à inserção da variável ambiental no planejamento urbano, verifica-se, no entanto, a potencialidade de o Plano Diretor Municipal contribuir para uma gestão hídrica local que seja ambientalmente sustentável e influencie na melhoria progressiva da qualidade e quantidade hídricas no âmbito das bacias hidrográficas. Do mesmo modo, com uma participação mais expressiva do município no Comitê de Bacia, é possível que as formas de ocupação e uso do solo municipal sejam consideradas no momento de elaboração e execução dos Planos de Bacia.

Outro instrumento que traz oportunidades para uma gestão integrada das águas é o Zoneamento Municipal, também presente no Estatuto da Cidade, e que possibilita a prevenção de impactos ambientais derivados da expansão urbana e demais usos do solo também no meio rural. Quando realizado de forma participativa, possibilita que atores sociais preocupados com a questão socioambiental interfiram em seu processo de elaboração, de modo a impedir que interesses puramente econômicos prevaleçam. Além disto, há casos de consórcios intermunicipais organizados em bacias hidrográficas, previstos na PNRH, que facilitam a gestão integrada das águas, agregando objetivos comuns de melhoria da disponibilidade hídrica em termos qualitativos e quantitativos no momento de elaboração e revisão de Planos de Bacias Hidrográficas.

\section{AGRADECIMENTOS}

Ao Departamento de Biologia e Zootecnia da Faculdade de Engenharia de Ilha Solteira (FEIS) da Universidade Paulista "Júlio de Mesquita Filho" (UNESP), pelo espaço concedido à pesquisa.

\section{REFERÊNCIAS}

ALMEIDA, F. G.; PEREIRA, L. F. M. O papel da distribuição e da gestão dos recursos hídricos no ordenamento territorial brasileiro. In: ALMEIDA, F. G.; SOARES, L. A. A. (Orgs.). Ordenamento territorial: coletânea de textos com diferentes abordagens no contexto brasileiro. Rio de Janeiro: Bertrand Brasil, 2009. p. 85-114.

AGÊNCIA NACIONAL DE ÁGUAS - ANA (Brasil). O comitê de bacia hidrográfica: prática e procedimento. Brasília, DF, 2011. (Cadernos de Capacitação em Recursos Hídricos, v. 2).

BASSUL, J. R. Reforma urbana e estatuto da cidade. EURE, Santiago, v. 28, n. 84, p. 133-144, 2002.

BRASIL. Constituição da República Federativa do Brasil. Brasília, DF: Senado Federal, 1988.

BRASIL. Lei $\mathrm{n}^{\circ}$ 9.433, de 8 de janeiro de 1997. Institui a Política Nacional de Recursos Hídricos, cria o Sistema Nacional de Gerenciamento de Recursos Hídricos, regulamenta o inciso XIX do art. 21 da Constituição Federal, e altera o art. $1^{\circ}$. da Lei ${ }^{\circ}{ }^{8} 8.001$, de 13 de março de 1990, que modificou a Lei $\mathrm{n}^{0} 7.990$, de 28 de dezembro de 1989. Diário Oficial [da] União, 8 de janeiro de 1997, Brasília, DF.

BRASIL. Lei $\mathrm{n}^{\circ} 10.257$, de 10 de julho de 2001. Regulamenta os arts. 182 e 183 da Constituição Federal, estabelece diretrizes gerais da política urbana e dá outras providências. Diário Oficial [da] União, 10 de julho de 2001, Brasília, DF. 
CARNEIRO, P. R. F.; CARDOSO, A. L.; AZEVEDO, J. P. S. O planejamento do uso do solo urbano e a gestão de bacias hidrográficas: o caso da bacia dos rios Iguaçu/Sarapuí na Baixada Fluminense. Cadernos Metrópole, v. 19, p.165-190, 2008.

CARTER, N.; KREUTZWISER, R. D.; LOË, R. C. Closing the circle: linking land use planning and water management at the local level. Land Use Policy, v. 22, p.115-127, 2005.

CASTRO, F. V. F.; AlVARENGA, L. J.; MAGAlHÃES JÚNIOR, A. P. A Política Nacional de Recursos Hídricos e a gestão de conflitos em uma nova territorialidade. Geografias, v.1, n. 1, p. 37-50, 2005.

EMPINOTTI, V. Avaliação dos 20 anos do Sistema Integrado de Gerenciamento de Recursos Hídricos - SIGRH. Relatório Final. 2010. Disponível em: http://www.sigrh.sp.gov.br/cgibin/sigrh_carrega.exe?f=/index/informe_files/informe2720anosSIGRH.html.

JACOBI, P. Governança institucional de problemas ambientais. Política \& Sociedade, v. 7, p. 119-137, 2005.

JOURAVLEV, A. Los municipios y la gestión de los recursos hídricos. Santiago: CEPAL, 2003. 72p. (Recursos Naturales e Infraestructura, v. 66).

LEAL, M. S. Gestão ambiental de recursos hídricos: princípios e aplicações. Rio de Janeiro: CPRM, 1998. 122p.

MACHADO, P. A. L. Direito ambiental brasileiro. 21. ed. São Paulo: Malheiros, 2013.

MILARÉ, E. Direito do ambiente: doutrina, prática, jurisprudência, glossário.4. ed. São Paulo: Revista dos Tribunais, 2005.

PERES, R. B.; SILVA, R. S. Análise das relações entre o Plano de Bacia Hidrográfica TietêJacaré e os Planos Diretores Municipais de Araraquara, Bauru e São Carlos, SP: avanços e desafios visando a integração de instrumentos de gestão. Revista Sociedade \& Natureza, v. 25, n. 2, 2013.

PINTO, E. M. A gestão de recursos hídricos e as interferências do sistema urbano: município de Queimados - RJ. Rev. Univ. Rural, Sér. Ciências Humanas. Revista Universidade Rural: Série Ciências Humanas, Seropédica, v. 29, n. 1, p. 125-131, 2007.

SANTOS, E. P.; MEDEIROS, Y. D. P. Possibilidades e limites de uma gestão integrada, adaptativa e democratizante das águas no Brasil. In: JACOBI, P. R.; SINISGALLI, P.

A. (Orgs.). Dimensões político institucionais da governança da água na América Latina e Europa. São Paulo: ANNABLUME, 2009. p. 82-102.

SILVA, R. T.; PORTO, M. F. A. Gestão urbana e gestão das águas: caminhos da integração. Estudos Avançados, v. 17, n. 47, p. 129-145, 2003.

TUNDISI, J. G.; MATSUMURA-TUNDISI, T. Recursos hídricos no século XXI. São Paulo: Oficina de Textos, 2011.

VASCONCELOS, M. E. G.; SILVA, P. M. U. Participação das Políticas Municipais na Gestão Sustentável de Bacias Hidrográficas. In: SIMPÓSIO BRASILEIRO DE RECURSOS HÍDRICOS, 20., 17-22 nov., Bento Gonçalves. Anais... Bento Gonçalves: ABRH, 2013. 